\title{
A ANÁLISE DAS REPRESENTAÇÕES E NARRATIVAS SOBRE A HISTÓRIA E CULTURA AFRICANA E AFRO-BRASILEIRA EM LIVROS DIDÁTICOS DO ENSINO MÉDIO EM CUIABÁ/MT
}

\author{
THE ANALYSIS OF REPRESENTATIONS AND NARRATIVES ABOUT AFRICAN \\ AND BRAZILIAN HISTORY AND CULTURE IN TEXTBOOKS OF MIDDLE \\ SCHOOL IN CUIABÁ / MT
}

\begin{abstract}
RESUMO: Este artigo pretende apresentar os resultados da pesquisa sobre as coleções de livros didáticos utilizados nas escolas públicas de Mato Grosso. Para tal selecionamos duas coleções, visando problematizar a abordagem contida nos livros acerca dos usos da narrativa sobre História e cultura africana e afro brasileira. As coleções escolhidas são: História Global de Gilberto Cotrim e coleção História: das cavernas ao terceiro milênio, das autoras Patrícia Ramos Braick e Myriam Becho Mota, ambas aprovadas pelo PNLD 2012 e destinadas ao público do Ensino Médio. A escolha destas coleções se deu, principalmente, por apresentar em seus editoriais a discussão sobre História e cultura africana e afro brasileira. Assim, fundamentamos a análise pela perspectiva teórico metodológica referente aos livros didáticos, à cultura e à lei $10.639 / 2003$.
\end{abstract}

Palavras-chave: História e cultura africana e afro brasileira. Livro didático.

Cultura.

ABSTRACT: This article intends to present the results of the research on the collections of textbooks, used in the public schools of Mato Grosso. For this we selected two collections, aiming to problematize the approach contained in the books, on the uses of the narrative on African and Afro Brazilian history and culture. The collections chosen are: Global History by Giberto Cotrim and collection History: from the caves to the third millennium, by the authors Patrícia Ramos Braick and Myriam Becho Mota, both approved by PNLD 2012 and destined to the public of the High School. The choice of these collections was mainly due to presenting in their editorials the discussion on African and Afro Brazilian history and culture. Thus, we base the analysis by the theoretical methodological perspective on textbooks, on culture and on the discussion of Law 10.639 / 2003.

Keywords: African and Afro Brazilian history and culture. Textbook. Culture.

\section{Introdução}

Este artigo analisa duas coleções de livros didáticos utilizadas pela Secretaria de Educação de Mato Grosso - "História Global: Brasil e Geral" e

\footnotetext{
${ }^{1}$ Doutora em História/UFSC, professora na graduação em História na UFMS, e na Pós Graduação em Educação. E professora no Mestrado Profhistória/UFMT.
} 
"História: das cavernas ao terceiro milênio". Na análise, pontuamos as discussões sobre as representações culturais de grupos afros presentes e ausentes nos textos e imagens dos livros. Fundamentamos, metodologicamente, a abordagem sobre a produção de discursos, compreendendo que os textos e imagens produzem sentido histórico e devem ser interpretados. Para tal, nos baseamos nas abordagens do livro didático como mediadores do processo de conhecimentos histórico, bem como facilitadores da apreensão de conceitos, do domínio de informações e de uma linguagem específica da área de cada disciplina. (BITTENCOURT, 2004, p. 296).

A escolha destes livros se deve às diferentes representações que trazem dos grupos africanos e afro brasileiros, principalmente após a Lei 10.639/2003 com a obrigatoriedade da História e cultura africana e afro brasileira. Assim, principiamos em aprofundar as discussões sobre a diversidade étnico-racial presente nas duas coleções de livros didáticos.

Pensar cultura é pensar o conjunto de conhecimentos, crenças e hábitos que as pessoas aprendem de modo dinâmico, a partir das relações de indivíduos e grupos, as quais exprimem em diferenças, identidades, imagens, pensamentos e textos. A cultura constrói comportamentos, valores, instituições e regras que confere sentido aos sujeitos e às suas práticas.

Em meio às inúmeras conceituações, a cultura pode ser entendida como tudo o que foi adquirido, apreendido e que pode ser transmitido; é um sistema de símbolos e significados. Compreende categorias ou unidades e regras sobre relações e modos de comportamentos. Mas, de acordo com Luis Gonzaga de Melo (1987, p. 41), a "[...] cultura não é apenas adquirida; ela é também transformada, mudada e acrescentada pela inovação ou descoberta". Já Roque de Barros Laraia (2009, p. 63) aponta que estudar a cultura é, portanto, estudar um código de símbolos partilhados pelos membros dessa cultura, e uma compreensão exata do conceito de cultura significa a compreensão da própria natureza humana, tema perene de incansável reflexão humana. 
Compreende-se o livro didático ${ }^{2}$ como uma ferramenta pedagógica utilizada num espaço escolar. Desta forma, utilizamos as noções de representações culturais como fundamento de normas, instituições, imagens; construção que encobre ordenamento, identificação, legitimação e exclusão. E, com isso, problematizamos de que forma a cultura africana e afro brasileira é representada nos livros analisados, pois como aponta Chartier (1990, p. 16), as representações "(...) são sempre determinadas pelos interesses de grupo que as forjam. Daí, para cada caso, o necessário relacionamento dos discursos proferidos com a posição de quem os utiliza"*

Embora a História da África e dos povos afrodescendentes sejam temas recorrentes na historiografia utilizada no ensino de História, ainda há lacunas e carecemos de mais pesquisas e práticas no entendimento e cumprimento da Lei n. 10.639/2003. Isso porque, como fundamenta Hilton Costa, o ensino da História e cultura africana e afro-brasileira pode ser representado como "[...] fruto de uma luta de anos dos movimentos sociais da população negra" (2012, p. 222). Nilma Lino Gomes (2012, p. 108) sugere que é necessário haver mais pesquisas que articulem diversidade étnico-racial, mas sem o risco da folclorização da cultura afro-brasileira.

A partir da Lei $n$. 10.639/2003 percebe-se que há um enfoque em diferentes espaços para o estudo da História e cultura africana e afro brasileira, o qual, também, ocorreu nos livros didáticos. Entretanto há, ainda, algumas concepções que precisam ser analisadas, como observa Renilson R. Ribeiro (2007, p. 46), sobre a secundarização de temas africanos nas páginas dos livros didáticos, pois os negros ainda "[...] são descritos como submissos, inferiores, exóticos - sujeitos distantes do que se convenciona chamar de sujeito universal: europeu, branco, masculino e cristão".

A respeito da mesma Lei, Kabenguele Munanga (2010, p. 48) salienta que, quando de sua promulgação, houve rejeição por parte de pessoas que questionavam a generalização do ensino obrigatório da História da África e

\footnotetext{
${ }^{2}$ Entendemos que o livro didático é uma ferramenta utilizada diariamente na experiência em sala de aula; dessa forma, consideramos que a sala de aula, espaço produtor de conhecimento histórico, em que os conteúdos presentes nas páginas dos livros didáticos produzem algum sentido para os envolvidos, constitui-se o lugar de representação e, ao mesmo tempo, o lugar de apropriação, pois tais sentidos são recebidos e reelaborados pelos atores sociais.
} 
do negro brasileiro. Na mesma perspectiva, Hilton Costa (2012, p. 222) observa que a Lei desde a sua sanção foi objeto de inúmeros debates "[...] que proporcionaram uma fortuna crítica bastante extensa, ainda mais porque no mesmo período ganham espaço no Brasil as políticas de ações afirmativas para a população negra".

A Lei $10639 / 2003$ trouxe modificações na produção de textos, inclusive com exigências por parte do Guia do Programa Nacional do Livro Didático (PNLD). Para perceber os encaminhamentos da inserção de textos e imagens que tivessem a lei 10639/2003 como direcionamento da construção dos livros analisamos o que consta no PNLD 2012 (p. 20). Sobre a abordagem da História e cultura africana e afro brasileira, o texto apresenta que:

Na historiografia brasileira, [...] tem-se demonstrado, ao longo das últimas décadas, que nossa sociedade é marcada pela diversidade e pela pluralidade étnica, religiosa, cultural, características resultantes dos seus próprios processos histórico-sociais, lutas, resistências, condicionamentos e escolhas. [...] Pode-se afirmar, assim, que no âmbito da produção acadêmica já foram abandonadas visões historiográficas que ignoravam a pluralidade étnicocultural da sociedade brasileira (grifo nosso) e que explicavam a formação da nossa nacionalidade pela "síntese das três raças: brancos, negros e indígenas". Abordagens pejorativas, visões preconceituosas e tratamentos estereotipados dos povos afrodescendentes e indígenas já não estão presentes também na produção didática (grifo nosso).

É importante registrar, ainda, que o interesse pela temática cultura africana e afrobrasileira se deu por tratar de assunto relevante para a comunidade escolar e para a sociedade de uma forma geral, pois aborda as questões relativas ao reconhecimento e à valorização das diferenças culturais. Os livros didáticos, segundo Choppin (2002, p. 14), "são depositário de um conteúdo educativo, o manual tem, antes de mais nada, o papel de transmitir às jovens gerações os saberes, as habilidades (mesmo o "saber-ser")". Destacamos que continua sendo o material de grande referência aos professores nas suas práticas em sala de aula. 


\section{Análise das coleções didáticas}

Realizamos o levantamento dos livros escolhidos e neles selecionamos os usos do conceito de cultura africana e afro brasileira, e as representações sobre os grupos afros em seus conteúdos. A metodologia utilizada baseou-se nas análises dos textos e imagens, pensando que estes produzem discursos. Além disso, optamos pelas coleções que tiveram maior inserção nas escolas estaduais, fundamentando-nos, metodologicamente, na análise de discurso, compreendendo como suporte de métodos pedagógicos, associando conteúdo e método, o livro didático caracteriza-se por "[...] conter exercícios, atividades, sugestões de trabalhos individuais ou em grupo e de formas de avaliação do conteúdo escolar" (BITTENCOURT, 2004, p. 302).

A abordagem proposta neste artigo utiliza a fundamentação de Michel de Certeau sobre a leitura e a produção editorial como formas de apreensão das "práticas sociais", em que texto e imagem produzem sentido e, no caso dos livros didáticos, produzem conhecimento histórico. Já que imagem e textos podem ser "[...] modelos culturais [...] necessários para o povo em vista de uma educação dos espíritos e de uma elevação dos corações [...] e o público é modelado pelos produtos que Ihe são impostos (CERTEAU, 1990, p. 260).

Assim, na análise realizada, compreendemos o livro didático como um produtor de sentido com representações sociais que, segundo Roger Chartier:

[...] não são de forma alguma discursos neutros: produzem estratégias e práticas (sociais, escolares, políticas) que tendem a impor uma autoridade à custa de outros, por elas menosprezados, a legitimar um projeto reformador ou a justificar, para os próprios indivíduos, as suas escolhas e condutas (CHARTIER, 1990, p. 17).

Nesse sentido, pensar que os atos de leitura que dão aos textos significações plurais e móveis situam-se no encontro de maneiras de ler, coletivas ou individuais, herdadas ou inovadoras, íntimas ou públicas e de protocolos de leitura depositados no objeto lido, não somente pelo autor 
que indica a justa compreensão de seu texto, mas também pelo impressor que compõe as formas tipográficas, seja com um objetivo explícito, seja inconscientemente, em conformidade com os hábitos de seu tempo (CHARTIER, 1996, p. 78).

Umas das coleções escolhidas foi Coleção História Global: Brasil e Geral, conforme registra o SIMAD - Sistema do Material Didático - cujo acesso se dá pelo Portal do FNDE (Fundo Nacional de Desenvolvimento da Educação), a coleção História Global: Brasil e Geral (Fig. 1), do autor Gilberto Cotrim, Editora Saraiva, 2010, aprovada pelo PNLD 2012 ao público do Ensino Médio, foi a mais distribuída ${ }^{3}$ na Rede Estadual de Ensino do Estado de Mato Grosso.

Figura 1:

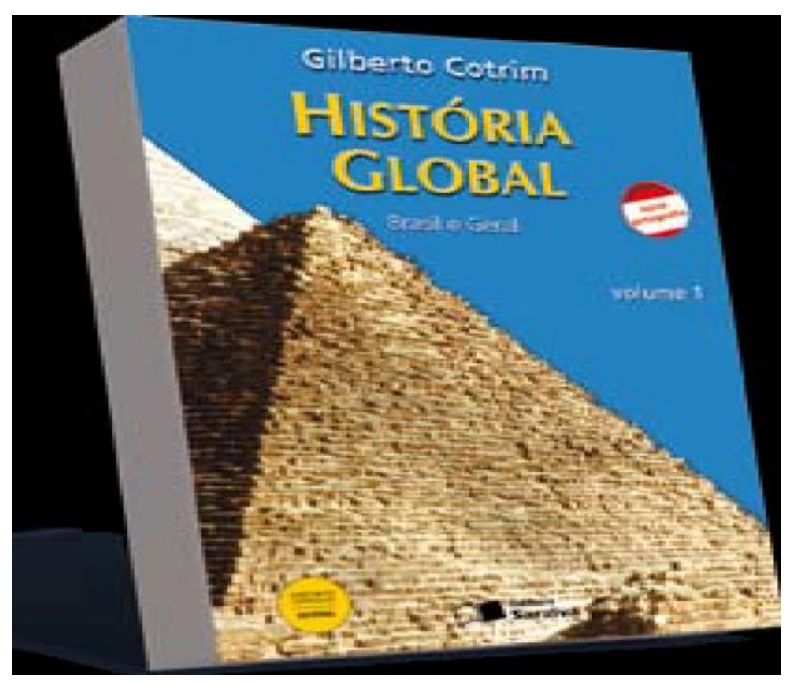

Fonte: acervo pessoal.

$\mathrm{Na}$ apresentação inicial do livro observamos a narrativa e justificativa do autor, o qual salienta que "a perspectiva de uma visão global sobre os conteúdos históricos foi organizada "em 23 capítulos divididos em 4 unidades que englobam História Geral e do Brasil" (COTRIM, 2010, p 4). A

\footnotetext{
${ }^{3}$ Foram distribuídas em, aproximadamente, 75 escolas, conforme levantamento realizado em 1/10/2016, no SIMAD - Sistema do Material Didático, disponível no Portal do FNDE Fundo Nacional de Desenvolvimento da Educação, cujo acesso se dá pelo link: http://www.fnde.gov.br/.
} 
seção Treinando o olhar, proposta na abertura dos capítulos, sempre apresentada por uma "imagem (que pode ser pintura, escultura, objeto ou charge", objetiva aguçar a curiosidade dos alunos, instigando-os a reconhecer recursos das linguagens artísticas, seus agentes e o contexto envolvidos na sua produção, levando-os às múltiplas reflexões acerca do conteúdo a ser estudado.

Ao final do capítulo, a obra traz a seção Oficina da História, composta de questões que utilizam diversos documentos históricos e reflexões de historiadores e intelectuais com o objetivo de estimular o aluno à produção de "textos analíticos e interpretativos sobre os processos históricos, comparar problemáticas atuais e de outros momentos históricos, tomar posição diante de questões contemporâneas, utilizando interpretações históricas etc" (COTRIM,2010, p. 11). Essa perspectiva de argumentação em que os textos e documentos contribuem para as reflexões de historiadores sobre os livros didáticos se dá no que Alain Choppin (2000, p. 13) aponta, pois:

\begin{abstract}
Em los últimos veinte anõs, el manual escolar se ha convertido, en un gran número de países, en una de las fuentes privilegiadas tanto por historiadores Del libro como por historiadores de la educación. La multiplicación de estúdios sobre la historia del libro y la edición escolares forma parte, sin duda alguna, de los avances que conoce la historia del libro, desde comienzos de la década de los ochenta1, además de relacionarse con el aumento de la capacidad de almacenamiento y los progresos de las técnicas de tratamiento de la información.
\end{abstract}

No livro de Gilberto Cotrim, no Capítulo 4 - Escravidão e resistência, impresso nas páginas 39 a 51, o autor foca suas discussões no tráfico negreiro e na resistência à escravidão, trazendo grande contribuição do historiador africano Joseph Ki-Zerbo (apud COTRIM, 2010, p. 42), que trata do impacto do tráfico negreiro na África:

[...] o tráfico custou a vida de milhões de africanos, que foram arrancados a este continente e expedidos, em condições atrozes, para além do Oceano Atlântico. Nenhuma coletividade humana foi mais inferiorizada do que os negros depois do século XV. [...] Os escravos eram comprados às toneladas. [...] O tráfico foi o ponto de partida de uma desaceleração, um arrastamento, uma paragem da história 
africana. [...] Se ignorarmos o que se passou com o tráfico negreiro, não compreenderemos nada sobre a África.

Percebe-se que há uma tentativa de evidenciar os diferentes grupos afros, mesmo que apenas citando-os. Além dessa parte há, no capítulo em questão, o texto: Culturas africanas, o qual destaca que:

[...] apesar de terem chegado ao Brasil sob as mais penosas condições, os africanos participaram intensamente das vivências culturais brasileiras. Essa participação deu-se por meio de um processo contínuo, rico e diversificado, sendo marcante, por exemplo, na literatura, na língua falada, no vocabulário, na música, na alimentação, na religião, no vestuário e na ciência. [...] Espalhadas por todas as regiões do país, as culturas africanas integram o modo de ser, pensar e viver da população brasileira. Do mesmo modo, o trabalho do africano marca a economia brasileira no passado e no presente.

Percebe-se que esta parte do texto está em consonância com a valorização da cultura africana e afro brasileira, buscando salientar a representação dos grupos afros como participantes do processo social e cultural. Ainda no texto Culturas africanas, (COTRIM, 2010, p. 45), o autor aborda um trecho de Pierre Verger, destacando que:

[...] a permanência visível de costumes africanos na cultura baiana pode ser explicada, em parte, pela concentração no último século da escravidão, de africanos de uma mesma procedência da África nessa região do Brasil. Enquanto, no Rio de Janeiro, desembarcavam africanos de todas as nações, [...], na Bahia chegavam escravos jejes (daomeanos), ussás e nagôs provenientes da Costa da Mina, que mantinham identidades culturais e erram unidos entre si.

No que diz respeito às estratégias e resistências praticadas pelos afrodescendentes, é proposto, no texto do livro intitulado Explorar \& Refletir, uma abordagem que apresenta a trajetória dos negros (COTRIM, 2010, p. 49) "durante as caminhadas nos sertões africanos, nos barracões das feitorias, a bordo dos navios tumbeiros ou nas cidades e plantações, o cativo lutou, como pôde, contra a escravidão". Para os estudantes, o autor propõe trazer as experiências dos povos afro-brasileiros para o espaço escolar, sugerindo que se (COTRIM, 2010, p. 49) "pesquise uma comunidade remanescente de quilombo em seu estado ou região. Elabore 
um texto sobre sua história, sua população e seu modo de ser e de viver. Depois, apresente-o a seus colegas".

Percebe-se que o texto descreve pouco a trajetória dos grupos africanos e afro brasileiros, ressalta suas ações enquanto escravos, o que pode encaminhar uma leitura e intepretação por parte dos estudantes. A proposta de pesquisa das comunidades quilombolas pode auxiliar na compreensão da vivência dos grupos culturais, mas sem uma perspectiva didática que problematize essa abordagem pode-se ter apenas um conhecimento superficial. Martha Abreu e Hebe Mattos (2008, p. 15), ao abordarem a questão das diretrizes curriculares com o conhecimento sobre as comunidades quilombolas, afirmam que

[...] o ensino de história afro-brasileira que abarque, com prioridade, iniciativas e organizações negras. $O$ texto completo relativo a essa sugestão envolve diversos e diferentes elementos, que muitas vezes sugerem uma continuidade básica e estrutural da história e da cultura afrobrasileira, quando, por exemplo, relaciona o quilombo de Palmares, do século XVII, com as comunidades negras hoje classificadas como remanescentes de quilombos.

Neste sentido, pode-se dizer que o autor visa entrelaçar as discussões propostas nas diretrizes curriculares sobre a inserção da História e cultura africana e afro brasileira. Na seção Explorar \& Refletir, no espaço Oficina de História ${ }^{4}$ (2010, p. 290), que é proposto no final do Capítulo 23 Segundo Reinado: últimas décadas há alguns encaminhamentos, para análise dos estudantes, sobre as concepções relacionadas aos grupos afros no Brasil:

Leia a afirmação abaixo: "Mais de um século depois da abolição da escravatura no Brasil, ainda pesa sobre os negros e seus descendentes uma série de problemas e discriminações sociais." Você concorda com ela? Ou, em sua opinião, os brasileiros realmente vivem numa democracia racial? Procure exemplos no seu dia a dia, no meio onde você vive. O que você encontra? Apresente suas observações aos colegas e debata com eles o assunto.

Consideramos que, a partir desses trechos do livro didático, é necessário conceituar democracia racial, trazendo, por meio de incentivo às

\footnotetext{
${ }^{4}$ Tal espaço propõe questões com o objetivo de ampliação do saber histórico sobre os temas abordados nos capítulos.
} 
pesquisas sobre as relações raciais no Brasil, as observações das Diretrizes Curriculares Nacionais para a Educação das Relações Étnico-Raciais e para o Ensino de História e Cultura Afro-Brasileira e Africana, que "trazem para o âmbito da escola, pela primeira vez, a importante discussão das relações raciais no Brasil e o combate ao racismo" (ABREU \& MATOS, 2009, p. 9).

A outra coleção que analisamos - aprovada pelo PNLD 2012 ao público do Ensino Médio - é História: das cavernas ao terceiro milênio (Fig. 2), das autoras Patrícia Ramos Braick e Myriam Becho Mota, divulgada pela Editora Moderna, 2010. Segundo o SIMAD - Sistema do Material Didático, disponível no Portal do FNDE - Fundo Nacional de Desenvolvimento da Educação - é a segunda coleção mais distribuída na Rede Estadual de Ensino do Estado de Mato Grosso ${ }^{5}$.

\section{Figura 2:}

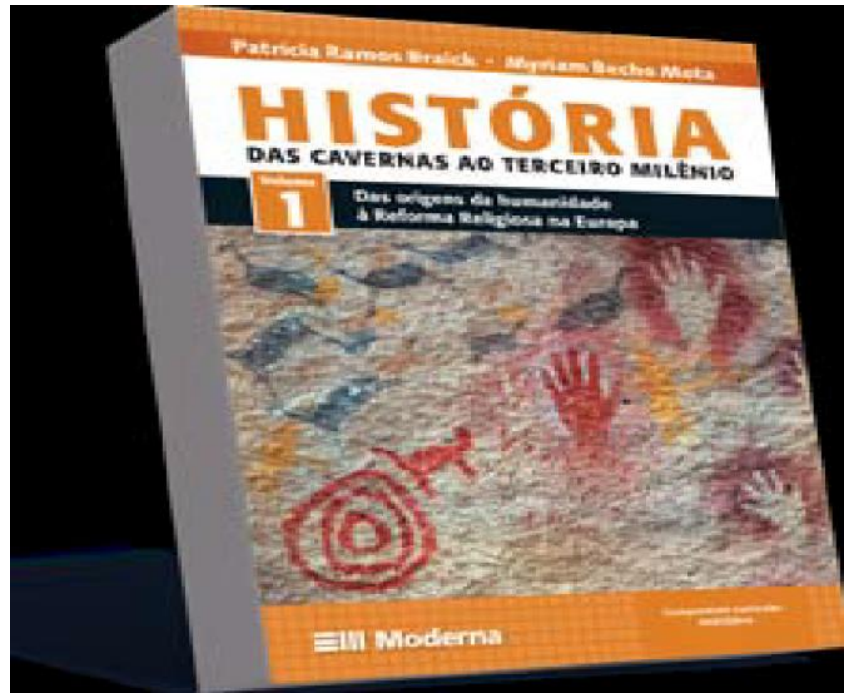

Fonte: acervo pessoal.

Sua estrutura é composta por seções (2011), como a denominada Páginas de abertura de Unidade. Consta, na seção Páginas de abertura de capítulo, com destaque aos recursos para motivar o aluno ao estudo dos conteúdos, que:

\footnotetext{
${ }^{5}$ Foram distribuídas em 48 escolas, aproximadamente, conforme levantamento realizado em 1/10/2016, no SIMAD - Sistema do Material Didático, disponível no Portal do FNDE Fundo Nacional de Desenvolvimento da Educação, cujo acesso se dá pelo link: http://www.fnde.gov.br/.
} 
[...] diferentes gêneros textuais e iconográficos, seguidos de um texto didático, introduzem o tema do capítulo. Quaisquer que sejam os recursos, a abertura apresenta uma problemática atual, que estabelece a ponte passado-presente e contribui para motivar o estudo dos conteúdos do capítulo.

Segundo as autoras, na seção Analise o documento há momento em que "partindo da ideia ampliada do que pode ser caracterizado como um documento histórico, esta seção leva o aluno a estabelecer relações entre diferentes conteúdos e a interpretar variados tipos de textos e imagens", possibilitando posicionar-se frente ao documento, realizando interpretações e pontos de vista. Já na seção Atividades (BRAICK \& MOTA, 2011, p. 12), no item Explorando o conhecimento,

[...] as questões propostas [...] têm como finalidade sistematizar os conteúdos estudados no capítulo e desenvolver habilidades cognitivas próprias da disciplina e da prática educativa, em especial a comparação, a observação, a interpretação, a produção de textos, o juízo crítico e as noções de cronologia.

Consideramos que as autoras propõem 'romper' com as práticas da historiografia tradicional; ou seja, a inserção de textos e atividades que buscam o reconhecimento das sociedades africanas, apresentando "[...] diversos aspectos da cultura negra tais como: carnaval, festas, [...] nacionalização e desafricanização de elementos da cultura popular, religiões afro-brasileiras, [...] samba, capoeira, etc.". No que tange à historiografia tradicional, Renilson Rosa Ribeiro (2007, p. 46) afirma a necessidade de novos olhares sobre a versão oficial, que apresenta quase sempre os negros, nas páginas dos livros didáticos, como "[...] submissos, inferiores, exóticos - sujeitos distantes do que se convenciona chamar de sujeito universal: europeu, branco, masculino e cristão".

No Capítulo 2: A África dos grandes reinos e impérios, as autoras dedicam, aproximadamente, 14 (quatorze) páginas sobre a História da África, destacando que "[...] conhecer a história dos povos africanos é entender ainda melhor a origem do povo brasileiro". Ressaltam, no texto Descobrindo a África, na página 26, que os negros africanos não vieram voluntariamente para a América portuguesa, pois foram obrigados, e que, mais do que mão-de-obra para o trabalho, nos porões dos navios negreiros 
"viajavam também culturas, idiomas e religiões estranhos aos portugueses" (BRAICK \& MOTA, 2010, p. 26).

No livro didático, na página 28 , a coleção traz no texto As línguas africanas, elementos que possibilitam perceber a variedade linguística da África e as influências de outras línguas externas na sua cultura, o que a caracteriza como espaço multicultural:

Na África falam-se mais de mil línguas. Algumas delas são utilizadas por milhões de pessoas, como o mandinga, o igbo, o ioruba e o hauçá, no oeste; o suaíli, no leste; o amárico e o orono, no noroeste; o zulu e o soto, no sul; e o árabe, no norte.[...] Como as culturas da África não estão livres de influências externas, muitos africanos passaram a falar, também, línguas europeias, como inglês, francês, português.

Busca, ainda, no texto $A$ influência africana na música (BRAICK \& MOTA, 2011, p. 79) demonstrar a importância das contribuições da África para a História do mundo, ao apontar que:

[...] a África influenciou fortemente a música contemporânea, tanto a popular quanto a chamada erudita ou clássica. Quase todos os ritmos populares difundidos do continente americano para o resto do mundo [...] tem raízes africanas.

Nota-se que a contribuição da cultura africana está em consonância com as ações educativas de combate ao racismo e às discriminações, propostas através do ensino de História e Cultura Afro-Brasileira e Africana. Na seção Analise o documento (BRAICK \& MOTA 2011, p. 33), localizada no Capítulo 2 - A África dos grandes reinos e impérios - é apresentado o texto As máscaras africanas, destacando a importância da utilização de máscaras (Fig.3) em cerimoniais religiosos praticados pelas sociedades africanas:

A utilização de máscaras em cerimoniais é prática comum há milhares de anos. Elas são de fundamental importância nos rituais, sejam de iniciação, de passagem ou de evocação de entidades espirituais. As máscaras apresentam-se, também, como elementos de afirmação étnica, expondo características particulares de cada grupo. 


\section{Figura 3:}

As máscaras africanas

"A utilização de máscaras em cerimoniais é prática comum há milhares de anos. Elas são de fundamental importåncia nos rituais, sejam de in ciação, de passagem ou de evocaçăo de entidades espirituais. As máscaras apresentam-se, também, como elementos de afirmação étnica, expondo caracteristicas particulares de cada grupo. Assim, existe uma enorme diversidade de formas, modelos, técnicas de confecção e aplicaçōes. [...]

técnicas de confecção e aplicaçōes. [...]
$\mathrm{Na}$ Affrica, o artifice, antes de começar a esculpir uma máscara, passa por um processo de purificação, com reza aos espiritos ancestrais e às forçà divinas. Tal prática faria com quie a força divina fosse transferida para a máscara durante o processo de manufatura.

Se no passado era prática generalizada, o uso de máscaras rituais teve um enorme declínio nas últimas décadas. Por isso, já existem pessoas que trabalham pela preservação deste hábito milenar.

As máscaras são empregadas, basicamente,

em eventos sociais e religiosos. Além de representarem os espíritos ancestrais, em alguns casos

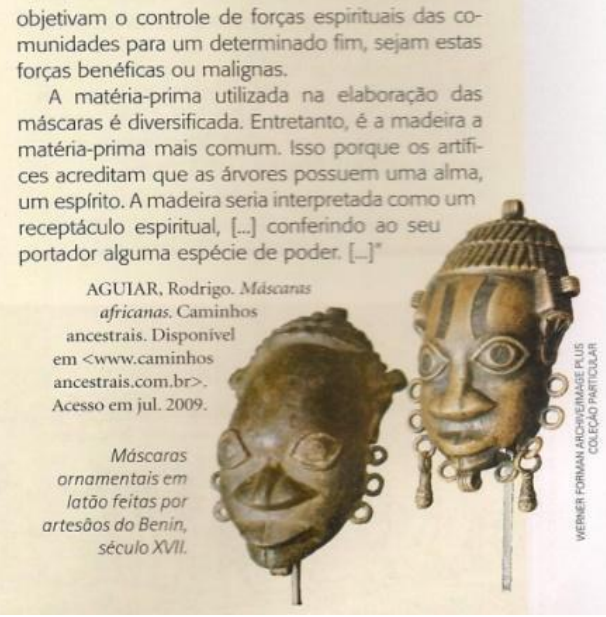

\section{Fonte: BRAICK.\& MOTA, livro didático das cavernas ao terceiro milênio.}

Buscando despertar o aluno ao interesse e à curiosidade no que tange à cultura africana, atividades relacionadas ao texto As máscaras africanas (BRAICK \& MOTA, 2011, p. 33) são apresentadas pelas autoras da coleção didática:

1. Sintetize o processo de fabricação de uma máscara africana.

2. Aponte as funções que as máscaras cumprem nas sociedades da África negra.

3. O que é um rito de passagem? Existe algum rito dessa espécie em sua cultura?

4. Você se recorda de outras sociedades que também utilizaram ou utilizam máscaras em festividades ou eventos sociais e religiosos? Quais?

Tal proposta objetiva reconhecer, valorizar e contribuir para a sobrevivência das religiões de matriz africana. De acordo com Flores (2016, p. 87), as religiões de matriz africana "[...] sempre viveram, e ainda vivem, perseguidas, ridicularizadas, roubadas de seu conteúdo filosófico e reduzidas a matérias folclóricas, [...] ao nível de magia negra e de superstição". As imagens contidas nos livros podem encaminhar conceitos e noções a partir das cenas históricas, as quais devem ser problematizadas, questionadas, para uma análise adequada, podendo até mesmo, realizar 
leituras externas ao livro, especialmente se recorre a livros antigos, condição ideal quando se quer fazer comparações (BITTENCOURT, 2001, p. 88).

É importante e necessário salientar que "[...] as práticas eurocêntricas devem ser extirpadas, pois assim poderá ser edificada uma nação pluri-étnica e multi-cultural em que haja respeito a todas as etnias que formam este país" (SILVA, 2009, p. 31).

Percebe-se que nas páginas dos livros didáticos, inclusive nos que estamos analisando, a necessidade de abordar as questões da História africana e afro brasileira e suas contribuições culturais, com intuito de romper com a visão estereotipada, e tratando para além dos artificialismos, da forma exótica, de construção por um prisma subalterno, mas, sim, pensar que as narrativas presentes nos livros didáticos devam "[...] lidar não apenas com o negro escravo, o negro que vive em condições precárias de sobrevivência, mas também a riqueza e problemas apresentadas por sua cultura, por sua atuação social, ou seja, com a multiplicidade de posições que ocupa ao longo da História. (OLIVEIRA, 2000, p. 170).

Nesse sentido, é importante perceber que nos livros didáticos, muitas vezes ressalta-se a História dos colonizadores, dos exploradores. Corrobora com essa perspectiva a questão 6, elaborada na seção Atividades:

Releia as informações sobre o Quilombo dos Palmares e faça uma ficha sobre o quilombo, destacando:

a) o que foi o Quilombo dos Palmares.

b) onde ele se localizava.

c) principais líderes do quilombo.

d) o desfecho da história do quilombo.

e) a importância para as autoridades portuguesas (grifo nosso) da vitória sobre Palmares.

Os pontos, suscitados na questão, enfocam e encaminham reforçar a importância que significou a resistência no Quilombo dos Palmares para os povos afro-brasileiros, memória presente com mais frequência em 20 de novembro, presumível data da morte do "herói" negro Zumbi dos Palmares, comemorada como o Dia Nacional da Consciência Negra.

No Capítulo 19: O governo de D. Pedro II, as autoras trazem na seção Analise o documento (BRAICK \& MOTA,2011 p. 297), a pintura (Fig. 
4) de Modesto Brocos intitulada $A$ redenção de Cam, um dos mitos idealizados por padres jesuítas com o objetivo de difundir a condenação bíblica do negro africano à escravidão, "justificando" sua escravização, anexada ao texto $A$ arte e as teorias raciais no século XIX, da autora Lilia Moritz Schwarcz, abordando as concepções estrangeiras sobre o fenômeno da miscigenação, seguido de Questões propondo pensar as teorias raciais do século XIX que alimentavam a utopia branca; ou seja, o branqueamento da população brasileira.

Figura 4 - A redenção de Cam, pintura de Modesto Brocos, 1895.

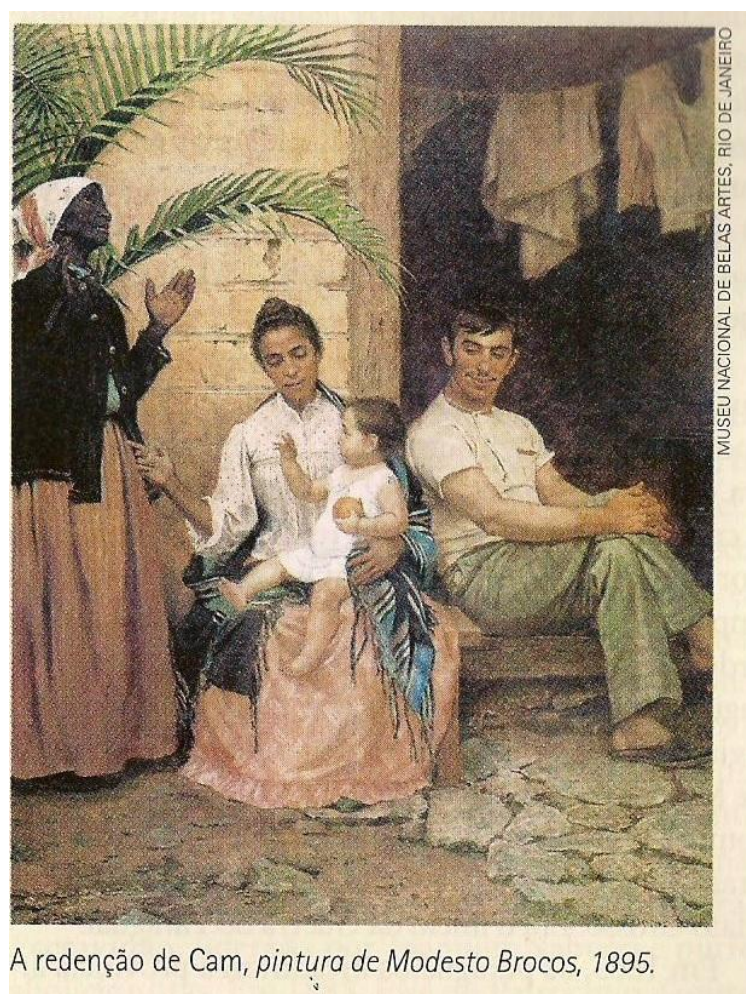

Fonte: BRAICK \& MOTA. História: das cavernas ao terceiro milênio.

Cabe esclarecer que, segundo José B. Silva Filho (2006, p. 108109) a Redenção de Cam:

Maldição de Cam foi baseada num episódio citado pelo Antigo Testamento no livro do Gênesis: 9:18-27, que relata um incidente ocorrido entre Noé e seus filhos Cam, Sem e Jafé. De acordo com o texto, Noé excedeu-se no vinho e dormiu despido. Seu filho, Cam, vendo-o naquele estado chamou 
seus irmãos para também observá-lo. Estes, porém, munidos de um lençol foram de costas e cobriram a nudez de Noé. O Sobrevivente do Dilúvio, ao acordar e saber do ocorrido, expulsou Cam de casa e condenou-o, com todos seus descendentes, à escravidão eterna.

Sobre as teorias raciais, que classificavam os negros e seus mestiços como "raças inferiores", a tese do "branqueamento", da "purificação étnica", realizada com a "infusão" de sangue europeu, associada aos projetos imigrantistas da década de 1880, pregava que o negro, por essa via, "[...] sucumbiria, física e culturalmente, ao avanço da civilização ocidental" (SEYFERTH , 1989, p. 12-13).

Na coleção História: das cavernas ao terceiro milênio, produzidas pelas autoras Patrícia Ramos Braick e Myriam Becho Mota, a avaliação do Guia concluiu o que se segue:

No que concerne à História e cultura da África, dos afrodescendentes e dos indígenas, no volume 1 são utilizados alguns objetos que pertencem à cultura de países africanos para exemplificar tipos de fontes históricas; há discussões sobre os desafios para a compreensão da História da África e abordam-se reinos e impérios africanos. No volume 2, são propostos textos e atividades que possibilitam conhecer questões da História recente do continente africano. Em outros capítulos deste volume, no estudo da colonização portuguesa na América, enfatizam-se a presença dos africanos e afrodescendentes e o papel que desempenharam como agentes transformadores de seu tempo. No volume 3, abordam-se o colonialismo e suas consequências em várias sociedades africanas na atualidade. (BRAICK \& MOTA, 2011, editoral)

Após analisar a coleção, constatamos que os objetos da cultura africana foram apresentados, conforme o texto As Máscaras Africanas registrado no Volume 2, Capítulo 2 - A África dos grandes reinos $e$ impérios. Tendo em vista que em tempos anteriores o continente africano foi ignorado nos currículos escolares, podemos considerar que a coleção ampliou a análise sobre o tema, pois apresenta os povos africanos como sujeitos atuantes na História. Identificamos que as preconizações da Lei no. 10639/03 e das Diretrizes Curriculares Nacionais para a Educação das Relações Étnico-Raciais e para o Ensino de História e Cultura Afro-Brasileira e Africana estavam presentes na coleção. Entretanto, algumas situações, como direcionar discussões sobre o tema em Boxes (quadros), ainda podem 
ser repensadas, pois muitas vezes tal espaço é ignorado nas práticas docentes.

\section{Algumas considerações finais}

A proposta deste artigo foi apresentar a pesquisa realizada com livros didáticos de História, do Ensino Médio, utilizados em Mato Grosso. Entre os livros pesquisados apresentamos as duas coleções mais utilizadas pelas escolas, principalmente as abordagens sobre a História e cultura africana e afro brasileira.

Percebe-se a intensificação das discussões, a inserção da lei 10639/2003, os encaminhamentos das diretrizes curriculares e do Programa Nacional do Livro Didático, os quais visam a ampliação das abordagens sobre a cultura e História dos grupos afros, numa perspectiva que envolva as dimensões críticas, contribuindo com sua valorização.

Na coleção História Global: Brasil e Geral do Gilberto Cotrim (2010), percebe-se a preocupação do autor em trazer estudiosos das questões africanas e afro brasileiras, mas ainda há alguns trechos no livro que seguem uma perspectiva que reforça estereótipos como, por exemplo, a abordagem sobre a abolição da escravidão no Brasil, que é creditada à Princesa Isabel.

Mas o autor traz o texto da Lei no. 10.639/03, rompendo com a prática conteudista da versão oficial, ao apresentar as diferentes manifestações da cultura afro-brasileira no território brasileiro, trazendo leituras complementares e atividades objetivando que os alunos reconheçam o valor civilizatório dos africanos e seus descendentes. Enumeramos, aqui, o texto Revolta da Chibata (1910), Reivindicações dos marinheiros, Cantos e chibatas e atividades propostas no Volume 3, com foco a desnaturalizar a versão oficial ao apresentar os africanos escravizados enquanto protagonistas nas páginas dos livros didáticos.

Quanto à coleção História: das cavernas ao terceiro milênio, das autoras Patrícia Ramos Braick e Myriam Becho Mota (2011), há uma preocupação em problematizar as contribuições africanas e afro brasileiras, com uso das imagens e nas discussões com as atividades propostas aos estudantes. 
Em suma, percebe-se que o livro didático compreendido como uma ferramenta didática nas aulas de História pode ser utilizado como um elemento de análise que problematiza as diferentes concepções históricas. Enfim, é preciso levar em conta a "[...] multiplicidade dos agentes envolvidos em cada uma das etapas que marca a vida de um livro escolar, desde sua concepção pelo autor até seu descarte pelo professor e, idealmente, sua conservação para as futuras gerações" (CHOPPIN, 2004, p. 553).

Assim, analisar de que forma os livros didáticos de História, utilizados no Ensino Médio, abordam a História e cultura africana e afro brasileira, permite ampliar e aprofundar as discussões sobre a contribuição cultural dos grupos afros, visando a

[...] transformação da representação social do negro no livro didático, como a convivência, por exemplo, é de grande importância no trabalho de formação de professoras e professores, para que as diferenças fenotípicas e culturais, entre outras, possam ser vistas sem estigmas e hierarquias (SILVA, 2011, p. 182).

Em suma, pode-se dizer que a lei 10.639/2003 objetivou uma educação que valorize a diversidade cultural, ampliando as noções históricas sobre a importância da cultura africana e afro brasileira e, neste sentido, as páginas dos livros didáticos podem contribuir para o florescimento de uma sociedade mais justa e igualitária e que valorize a diversidade cultural.

\section{Referências}

ABREU, Martha; MATTOS, Hebe. Em torno das Diretrizes curriculares nacionais para a educação das relações étnico-raciais e para o ensino de história e cultura afro-brasileira e africana: uma conversa com historiadores. Estudos Históricos, Rio de Janeiro, v. 21, n. 41, jan./jun. 2008.

BITTENCOURT, Circe M. F. (org.). O saber histórico na sala de aula. 9. ed. São Paulo: Contexto, 2004.

BRASIL. Guia de livros didáticos: PNLD 2012: História. Brasília: Ministério da Educação, Secretaria de Educação Básica, 2011.

BRAICK, P Patrícia; MOTA, Myriam B. História: das cavernas ao terceiro milênio. 2. ed. São Paulo: Moderna, 2011. v. 2. 
MEC, BRASIL. Guia de livros didáticos: PNLD 2012: História:Brasília: Secretaria de Educação Básica, 2011

COTRIM, Gilberto. História global: Brasil e Geral. São Paulo: Saraiva, 2010. v. 2.

COSTA, Hilton. Para construir outro olhar: notas sobre o ensino de história e cultura africanas e afro-brasileiras. Revista História Hoje, v. 1, n. 1, p. 217238, 2012.

CHARTIER, Roger. A História cultural: entre práticas e representações. Rio de Janeiro: Bertrand Brasil, 1990.

CHOPPIN, Alain. História dos livros e das edições didáticas: sobre o estado da arte. Educação e Pesquisa, São Paulo, v. 30, n. 3, p. 549-566, set./dez. 2004.

- Los Manuales escolares de ayer a hoy: el ejemplo de Francia. Historia de la Educación, n. 19, p. 13-37, 2000.

FILHO, José Barbosa da Silva. História do Negro no Brasil. Cadernos Penesb - Periódico do Programa de Educação sobre o Negro na Sociedade Brasileira, Niterói, n. 7, nov. 2006.

FLORES, Elio Chaves. Visões da África, cultura histórica e afro-brasilidades. João Pessoa: Editora da UFPB, 2016.

GOMES, Nilma Lino. Relações étnico-raciais, educação e descolonização dos currículos. Currículo sem Fronteiras, v. 12, n. 1, p. 98-109, jan./abr. 2012.

JESUS, N. M. de; CEREZER, O. M.; RIBEIRO, R. R. (orgs.). Ensino de História: trajetórias em movimento. Cáceres: Ed. UNEMAT, 2007.

LARAIA, Roque de B. Cultura: um conceito antropológico. 24. ed. Rio de Janeiro: Jorge Zahar Ed., 2009.

MELO, Luís G. Antropologia cultural: iniciação, teoria e temas. Petrópolis, Vozes, 1987.

MUNANGA, Kabengele. Educação e diversidade cultural. Cadernos Penesb, Niterói, n. 10, p. 1-200, jan./jun. 2008/2010.

OLIVEIRA, M. A. de. O negro no ensino de história: temas e representações. 2000. Dissertação (Mestrado em Educação) - Faculdade de Educação da Universidade de São Paulo, São Paulo, 2000.

SILVA, Ana Celia. A representação social do negro no livro didático: o que mudou? Por que mudou? Salvador: UFBA, 2011. 
RIBEIRO, Renilson R. Representações didáticas no Brasil Colonial. ETD Educação Temática Digital, v.8, n.2, p. 53-68, jun. 2007.

Recebido em 23 de setembro de 2018

Aprovado em 14 de março de 2019 